\title{
Conservation Research in Times of COVID-19- The Rescue of the Northern White Rhino
}

\author{
Thomas B. Hildebrandt* \\ Department of Reproduction Management, Leibniz-Institute for Zoo and \\ Wildlife Research, Alfred-Kowalke-Str. 17, 10315 Berlin, Germany \\ Freie Universität Berlin, D-14195, Berlin, Germany \\ hildebrandt@izw-berlin.de
}

\section{Susanne Holtze*}

Department of Reproduction Management, Leibniz-Institute for Zoo and Wildlife Research, Alfred-Kowalke-Str. 17, 10315 Berlin, Germany holtze@izw-berlin.de

\section{Pierfrancesco Biasetti}

Department of Reproduction Management, Leibniz-Institute for Zoo and Wildlife Research, Alfred-Kowalke-Str. 17, 10315 Berlin, Germany Ethics Laboratory for Veterinary Medicine, Conservation, and Animal Welfare, Università degli Studi di Padova, 35020 Padova, Italy biasetti@izw-berlin.de

\section{Silvia Colleoni}

Avantea, Laboratory of Reproductive Technologies, 2610o, Cremona, Italy Fondazione Avantea, 2610o, Cremona, Italy silviacolleoni@avantea.it

\section{Barbara de Mori}

Ethics Laboratory for Veterinary Medicine, Conservation, and Animal Welfare, Università degli Studi di Padova, 35020 Padova, Italy Department of Comparative Biomedicine and Food Science, Università degli Studi di Padova, 35020 Padova, Italy barbara.demori@unipd.it

\footnotetext{
* These authors contributed equally to this work.
} 


\author{
Sebastian Diecke \\ Technology Platform Pluripotent Stem Cells, Max Delbrück Center \\ for Molecular Medicine in the Helmholtz Association (MDC), \\ Robert-Rössle-Str. 10, 13092 Berlin, Germany \\ Berlin Institute of Health, Anna-Louisa-Karsch-Straße 2, \\ 10178 Berlin, Germany \\ Sebastian.Diecke@mdc-berlin.de
}

\title{
Frank Göritz
}

Department of Reproduction Management, Leibniz-Institute for Zoo and Wildlife Research, Alfred-Kowalke-Str. 17, 10315 Berlin, Germany goeritz@izw-berlin.de

\section{Katsuhiko Hayashi}

Department of Stem Cell Biology and Medicine, Graduate School of Medical Sciences, Kyushu University, Fukuoka, 812-0054, Japan

hayashik@hgs.med.kyushu-u.ac.jp

\section{Masafumi Hayashi}

Department of Stem Cell Biology and Medicine, Graduate School of Medical Sciences, Kyushu University, Fukuoka, 812-0054, Japan

hayashim@hgs.med.kyushu-u.ac.jp

\section{Robert Hermes}

Department of Reproduction Management, Leibniz-Institute for Zoo and Wildlife Research, Alfred-Kowalke-Str. 17, 10315 Berlin, Germany hermes@izw-berlin.de

\section{Linus Kariuki}

Kenya Wildlife Service, Nairobi, Kenya

lkariuki@kws.go.ke

\section{Giovanna Lazzari}

Avantea, Laboratory of Reproductive Technologies, 2610o, Cremona, Italy Fondazione Avantea, 2610o, Cremona, Italy giovannalazzari@avantea.it

\section{Domnic Mijele}

Kenya Wildlife Service, Nairobi, Kenya

dmijele@kws.go.ke 


\author{
Samuel Mutisya \\ Ol Pejeta Conservancy, 1040o Nanyuki, Kenya \\ samuel.mutisya@olpejetaconservancy.org \\ David Ndeereh \\ Kenya Wildlife Service, Nairobi, Kenya \\ david.ndeereh68@gmail.com
}

\title{
Stephen Ngulu \\ Ol Pejeta Conservancy, 1040o Nanyuki, Kenya \\ stephen.ngulu@olpejetaconservancy.org
}

\section{Steven Seet}

Science Management, Public Relations, Leibniz-Institute for Zoo and Wildlife Research, Alfred-Kowalke-Str. 17, 10315 Berlin, Germany seet@izw-berlin.de

\section{Jan Zwilling}

Science Management, Public Relations, Leibniz-Institute for Zoo and Wildlife Research, Alfred-Kowalke-Str. 17, 10315 Berlin, Germany zwilling@izw-berlin.de

\section{Vera Zywitza}

Technology Platform Pluripotent Stem Cells, Max Delbrück Center for Molecular Medicine in the Helmholtz Association (MDC), Robert-Rössle-Str. 10, 13092 Berlin, Germany

Vera.Zywitza@mdc-berlin.de

\section{Jan Stejskal ${ }^{\dagger}$}

Zoo Dvůr Králové, Štefánikova 1029, 544 o1, Dvůr Králové nad Labem, Czech Republic

jan.stejskal@zoodk.cz

\section{Cesare Galli ${ }^{\dagger}$}

Avantea, Laboratory of Reproductive Technologies, 2610o, Cremona, Italy Fondazione Avantea, 2610o, Cremona, Italy cesaregalli@avantea.it

$\dagger$ These authors jointly supervised this work. 


\begin{abstract}
COVID-19 has changed the world at unprecedented pace. The measures imposed by governments across the globe for containing the pandemic have severely affected all facets of economy and society, including scientific progress. Conservation research has not been exempt from these negative effects, which we here summarize for the BioRescue project, aiming at saving the northern white rhinoceros (Ceratotherium simum cottoni), an important Central African keystone species, of which only two female individuals are left. The development of advanced assisted reproduction and stem-cell technologies to achieve this goal involves experts across five continents. Maintaining international collaborations under conditions of national shut-down and travel restrictions poses major challenges. The associated ethical implications and consequences are particularly troublesome when it comes to research directed at protecting biological diversity - all the more in the light of increasing evidence that biodiversity and intact ecological habitats might limit the spread of novel pathogens.
\end{abstract}

\title{
Keywords
}

COVID-19 - northern white rhinoceros - conservation - Kenya - international cooperation - veterinary intervention - ageing - species extinction

\section{Introduction}

Since the beginning of 2020, the coronavirus disease 2019 (COVID-19), caused by the novel coronavirus SARS-CoV-2, has been increasingly recognized as a global threat. On March 11, 202O, it was declared a pandemic by the World Health Organization (WHO; WHO, 2O2O). The drastic consequential measures to attenuate its propagation have had vast effects on manifold aspects of professional activities across all sectors (Ferguson et al., 2020). Consequences of this "anthropause" (Rutz et al., 2020) for conservation have been controversially discussed. On the one hand, the abatement in human activities has led to a reduction in ambient pollution (Muhammed et al., 202O; Venter et al., 202O) and $\mathrm{CO}_{2}$-emissions (Le Quéré et al., 202O). Various species have benefitted (Manenti et al., 2020) and the closure of wet markets has led to reduced hunting pressure on wildlife (Borzée et al., 2020). On the other hand, overall funding for conservation agencies has decreased, their operations have been restricted (e.g., anti-poaching, management of wildlife and invasive species; Bates et al., 2020; Buckley, 202O) and human threats to nature elevated (Lindsey et al., 
2020), e.g., by a decrease in wildlife-based tourism (Lindsey et al., 2020), and increased pressure on natural resources in absence of other sources of income (Buckley, 2020).

Despite immense financial and logistic support for research centered on COVID-19, its treatment and the development of a vaccine, scientific progress in most fields outside of this scope has slowed down. The consequences in the area of conservation research are particularly dramatic. While working with species at the brink of extinction, time represents a very precious and crucial element and missed opportunities can easily result in irreplaceable loss.

We here present the specific consequences and ethical aspects arising from the various laws and rules to detain CoviD-19 around the globe on the efforts to save a species using the example of the northern white rhinoceros (NWR, Ceratotherium simum cottoni).

The disappearance of a charismatic megaherbivore such as the NWR represents not only a loss per se, but also that of a provider of important ecosystem services. White rhinos can be classified as keystone species by acting as landscape architects (Waldram et al., 2008; Cromsigt \& te Beest, 2014). Therefore, the absence of the NWR from its original distribution range across parts of Uganda, Chad, South Sudan, the Central African Republic, and the Democratic Republic of the Congo bears the potential to strongly impact large parts of the fragile ecosystems of Central Africa (Owen-Smith, 1988; Waldram et al., 2008). The long-term consequences of its extinction are not fully predictable, but certainly include a significant disturbance, if not destruction, of elements of the complex biological equilibrium, possibly initiating a so called "vortex effect". The term was coined by Bob Lacey (1993) and used to name his famous Vortex Population Viability Analysis software, freely available via the International Union for Conservation of Nature (IUCN). The vortex effect describes the accelerated loss of species and entire species societies whose life history directly or indirectly depend on threatened keystone species.

Currently, we are facing the earth's sixth great extinction event (Ceballos et al., 2017), with $22 \%$ of all mammalian species at risk of vanishing from the planet, largely due to anthropogenic activity. This mass extinction occurs at an unprecedented pace and bears significant negative consequences, not least for human society and economy (Ceballos et al., 2015). In this light, it becomes increasingly pressing to improve biodiversity by safeguarding ecosystems, 
species, and genetic variety. To stop, or even to slow down this process sufficiently, methods beyond traditional conservation measures - such as habitat protection and classical ex-situ conservation programs - will be needed.

Among threatened mammalian species, the family Rhinocerontidae is particularly affected (Di Minin et al., 2015; Emslie et al., 2013). Global populations of rhinoceros have declined alarmingly, from about 500,000 at the beginning of the 2oth century to 29,000 in 2016, largely due to an escalation of poaching for rhinoceros' horn (Biggs et al., 2013; Haas et al., 2016; Traffic, 2016). The current global rhino population is comprised of five species. According to the IUCN Global Red List of threatened species, three are listed as critically endangered (Sumatran, Javan, and black rhinoceros), one is listed as vulnerable (greater one-horned rhinoceros), and one, the southern white rhinoceros (swr, Ceratotherium simum simum), is listed as near threatened. By implementing hunting bans (Rookmaaker, 2000) and management strategies in the 195 os and 1960s (Player, 1967), the SWR has recovered from a dramatic population decline around 1900 to merely $20-50$ individuals (Emslie \& Brooks, 2002), now representing the most numerous rhinoceros species (Rhino population figures, 2021). Its northern counterpart, the NWR has been suspected extinct in the wild since 2008 by the IUCN; according to the latest assessment (Emslie, 2020), the subspecies is considered "Critically Endangered (Possibly Extinct in the Wild)".

The death of the last known male NWR, Sudan, on March 19, 2018 has increased international public attention to the hopeless fate of this subspecies. Concomitantly, it has given new urgency to the nascent development towards alternative measures of conservation. The BioRescue consortium (see Table 1) had recently emerged from a 2015 meeting in Vienna, where a group of international scientists from five continents had proposed a new strategic roadmap for saving the critically endangered NWR (Saragusty et al., 2016). At the time, Sudan was still alive and housed with the last two known females of his subspecies, Najin and Fatu. While saving the swR in the past century represents an impressive conservation success, saving the NWR at the current moment is a groundbreaking endeavor which will be successful only by pushing the boundaries of modern science (Saragusty et al., 2016).

The proposed novel and innovative approach combines advanced assisted reproductive technologies (aART) and stem-cell associated techniques (SCAT). Its goal is to develop suitable methods and protocols to ultimately establish a self-sustaining, genetically healthy NWR population, which can be reintroduced to the wild. Both approaches involve the use of biomaterial of live as well as deceased individuals in form of cryopreserved gametes (Hermes et al., 
2018) and skin samples for fibroblast cultures for SCAT. The stored biomaterial comprises approx. $300 \mathrm{ml}$ of cryopreserved semen from four different NWR bulls (Hermes et al., unpubl. data) and 12 NWR fibroblast cell lines representing eight presumably unrelated founders (Tunstall et al., 2018). Together with the last two living NWR females Najin and Fatu, which are not capable of carrying full pregnancy, but may serve as oocyte donors, this precious biomaterial constitutes the pillars for the success of saving the species.

The scope of aART is the minimally invasive collection of oocytes from female donors and the generation of viable embryos. These embryos will ultimately be transferred to surrogate mothers of the closely related SWR to give birth to a new generation of NWR. Time pressure for this approach arises due to the fact that the last two donor females, Najin and Fatu, are already 31 and 20 years old, respectively, and both their ability to produce viable oocytes as well as general health will decline with increasing age. It is therefore crucial to collect as many oocytes for embryo production as possible while both individuals are still in good condition. Several years of groundwork, rendered possible only by dedication of the entire team, have resulted in the generation of the first SWR and SWR/NWR hybrid embryos (Hildebrandt et al., 2018). Since 2019, the project has been financially supported by the German Federal Ministry of Education and Research (BмBF; Bio-Rescue, olLC19о2A) and has generated considerable public attention. As of today, altogether three purebred NWR embryos have been generated and stored in liquid nitrogen for future embryo transfer (unpubl. data).

The scope of the second approach, SCAT, involves fibroblast cultures. Via induced pluripotent stem cell transformation, these cells may be used for the subsequent in vitro production of artificial gametes. This has been successfully performed in mice (Hikabe et al., 2016) and is currently being translated to rhinoceros' cells. The advantage of this technique is the relative independence of living animals and the potential to generate large numbers of embryos. By optimally combining the gametes of all available individuals, the genetic diversity of the offspring can be maximized. Nevertheless, several years may be still needed to achieve these ultimate goals.

The production of healthy embryos derived from natural gametes (aART) and from cell culture generated artificial gametes (SCAT) will allow for the preservation of the NWR genome and the subsequent embryo transfer into surrogates using female swr. Beyond generating embryos, the project also has the potential to become a game-changing species conservation success story with immense value for conservation education (Ryder et al., 2020). The project also comprises an ethical risk analysis. When innovative research pushes the boundaries of feasibility, new risks may arise that have not yet been adequately 
assessed, accompanied by novel ethical considerations. These questions range from the well-being of individuals to the prosperity of a whole subspecies and complex social-ecological matters. Therefore, a systematic analysis of and public discourse on these topics are integral part of the BioRescue project.

Besides urgency imposed by the ageing of the two living females, additional pressure arises due to the fact that beyond the merely genetic contribution of their oocytes, the social aspect is of importance. Species-specific communication and skills can only be passed on to the next generation by their kind, and it is crucial to raise the first live offspring with the last NWR females to allow for such transfer.

An international team (see Table 1) working in a globalized framework is vulnerable on various levels to major disruptions of its workflow. We here describe the consequences of CoviD-19 on the BioRescue project on a local, national and international level including its positive and negative effects.

TABLE 1 Overview of institutions involved in the project and their main tasks

\begin{tabular}{|c|c|c|}
\hline Institution & Country & Main task in the project \\
\hline Ol Pejeta Conservancy (oPC) & Kenya & $\begin{array}{l}\text { Veterinary care and interventions, } \\
\text { animal husbandry, contribution to } \\
\text { both aART and SCAT }\end{array}$ \\
\hline Kenya Wildlife Service (KWs) & Kenya & $\begin{array}{l}\text { Competent authority on wildlife } \\
\text { matters in Kenya; Veterinary care, } \\
\text { interventions and supervision, } \\
\text { technical support }\end{array}$ \\
\hline $\begin{array}{l}\text { Leibniz Institute for Zoo and } \\
\text { Wildlife Research (IZW) }\end{array}$ & Germany & $\begin{array}{l}\text { aART: oocyte collection, embryo } \\
\text { transfer }\end{array}$ \\
\hline & & $\begin{array}{l}\text { SCAT: laboratory work, cell culture } \\
\text { Coordination, media, fundraising }\end{array}$ \\
\hline $\begin{array}{l}\text { Max Delbrück Center for } \\
\text { Molecular Medicine (MDC) }\end{array}$ & Germany & $\begin{array}{l}\text { SCAT: stem-cell related laboratory } \\
\text { work }\end{array}$ \\
\hline Kyushu University & Japan & $\begin{array}{l}\text { SCAT: stem-cell related laboratory } \\
\text { work }\end{array}$ \\
\hline Zoo Dvůr Králové & Czech Republic & $\begin{array}{l}\text { Coordination, fundraising, } \\
\text { logistics, media }\end{array}$ \\
\hline Avantea Srl & Italy & $\begin{array}{l}\text { aART: laboratory work for } \\
\text { generating embryos }\end{array}$ \\
\hline University of Padova & Italy & $\begin{array}{l}\text { Ethical assessment and } \\
\text { monitoring of the project }\end{array}$ \\
\hline
\end{tabular}




\section{Impairment of Conservation Work and Research for Saving the} Northern White Rhino

\subsection{Local and National Level}

On the local level, the work of the project team members within their respective countries - Kenya, Germany, Czech Republic, Italy, and Japan - has been negatively affected in various facets. Also, on the national level, a variety of obstacles have arisen within each involved country.

\subsubsection{Kenya}

In 2009, four NWR were translocated from Zoo Dvůr Králové in the Czech Republic to Ol Pejeta Conservancy (OPC), Kenya. This included the last two females, Najin and Fatu, as well as two males, Suni and Sudan, who died in 2014 and 2018, respectively. The last two northern white rhinoceros females are housed under constant surveillance of armed guards at Ol Pejeta Conservancy in Laikipia County in central Kenya. They roam in a 70o-acre enclosure and receive dietary supplements and state-of-the-art veterinary care. The large park $\left(36 \circ \mathrm{km}^{2}\right)$ is a non-profit wildlife reserve in Central Kenya, whose aim is to conserve wildlife, provide a sanctuary for great apes, and to generate income through wildlife tourism and complementary enterprises for re-investment in conservation and community development.

COVID-19 infection rates in Kenya have remained comparably low. Only approximately 300 confirmed cases have been recorded by the end of April 2020, and less than 100 deaths by the beginning of June (Mbogo \& Nyabadza, 2020). Mombasa region was affected most severely, but hospitals were not overwhelmed in any part of the country. Nevertheless, drastic measures have been applied by the government. A nation-wide curfew was implemented, the capital Nairobi isolated from the rest of the country, and all borders were closed. Travel within Kenya was restricted between April and August 2020 (Mbogo \& Nyabadza, 2020). Within Ol Pejeta, the chimpanzee area was temporarily closed for the public to avoid infections with CoviD-19. No cases have been recorded in Ol Pejeta, but the lockdown of the country and closure of the borders resulted in the absence of both foreign and national visitors, which caused severe losses in revenue. Therefore, fundraising was necessary to maintain the park and pay for salaries. Nevertheless, safeguarding the animals and professional veterinary care were maintained at all times, and aspects of importance to the project have been advanced. In cooperation with Kenya Wildlife Service, blood of both NWR was sampled under local analgesia and stored in liquid nitrogen as long as Nairobi was in lockdown. After re-opening of the capital in August, it was immediately sent to a veterinary 
laboratory for testing, as requested by the authorities for obtaining a health certificate for the next export of oocytes to Europe.

\subsubsection{Germany}

The Leibniz Institute for Zoo and Wildlife Research (IZW) is a German research institute within the Leibniz Association. The institute's goal is to enhance our understanding of wildlife adaptability in the context of global change and to enhance the survival of viable wildlife populations - in short, performing "Research for Species Conservation". During the measures imposed for confining the spread of COVID-19 in the spring of 2020, there was a general shutdown of scientific institutions in Germany. The Izw implemented a state of emergency operation (March 23 to April 28, 2020), during which only animal and emergency veterinary care were permitted, while the majority of staff were regularly working in home office. Most laboratory and travel activities were cancelled and interaction and communication between colleagues impaired. Indispensable travel activities were logistically challenging. The restricted research mode (April 29 to August 31, 2020) allowed for slightly more research activities and was finally replaced by the adjusted research mode (September ist until the end of 2020), which allows for work at the institute as long as distancing and hygiene rules are respected. Despite the restrictions, various activities have been carried out at the IZW: Fibroblasts have been successfully cultured from the hybrid Nasi (NWR/sWR, deceased in 2007) and from tissue samples of Sudan, Najin, and Fatu, collected in 2014 and imported in December 2019 from Kenya. Shipment to Cremona for the assessment of viability of the concomitantly imported semen samples at Avantea was delayed due to CoviD-19, but finally conducted.

The Max Delbrück Center for Molecular Medicine in the Helmholtz Association (MDC) is devoted to biomedical research with the aim of understanding the molecular basis of health and disease and translating findings into clinical applications. It offers a renowned Core Facility for Stem Cells. The situation at MDC during spring and summer 2020 has been similar to that at IZW. Only COVID-19 related research or long-lasting projects were allowed to be pursued, and only a limited number of staff per laboratory was allowed. Child care and schools were closed between March and August 2020, forcing parents from laboratory work to home office. In addition, delivery of research equipment for establishing a new stem cell and embryology laboratory at MDC and IZW, respectively, was severely delayed. Also the commissioning of new instruments was impaired due to national travel restrictions.

Both zoological facilities, Berlin Zoo and Tierpark Berlin, have been closed to the public for 15 weeks, (March 17 to April 28, 2020). A previously discussed swR enclosure at Tierpark Berlin for supporting the BioRescue project with embryo 
transfer (ET)-recipients has been postponed and may be entirely canceled due to severe financial losses of the zoological gardens during the covid-19 crisis. Such access to SWR females in close proximity would have been a major logistic improvement, allowing for close monitoring of both cycling activity for the optimal timing of embryo transfers as well as of resulting pregnancies. In absence of this option, embryo transfers will be performed in more distant European zoos, including the logistic impediment of regularly gathering exact information on the recipients. The nearest candidates are located at Schwerin Zoo, three hours from Berlin, and housed with a sterile teaser bull that reliably indicates estrous, comparable to the setting planned for Ol Pejeta, Kenya.

Despite the mentioned difficulties and the restriction to work in German zoos, several research activities were successfully performed.

- An oocyte collection (ovum pick-up, OPU) was performed in Schwerin Zoo on two female swr on May 5, 2020. Oocytes were sent via courier to the Avantea laboratories in Cremona, Italy, where after fertilization with swR semen an embryo was successfully generated and cryopreserved.

- A further OPU was performed in Serengeti-Park Hodenhagen on May 26, 2020 using the thus far youngest swr female ( 7 years). The permission to perform an oocyte collection in this female was granted by the European Association of Zoos and Aquaria (EAZA) Ex-situ Programme (EEP) for the White Rhino, since the shipment of a breeding partner from England had been suspended due to COVID-19. Under these circumstances, the use of aART represented the only option for breeding in this case. Altogether, 12 oocytes were collected, which is the highest number achieved so far in one procedure. Due to COVID-19-related transportation problems of the courier service, the arrival of the oocytes to Cremona was delayed. Nevertheless, four promising embryos developed and were cryopreserved.

- On June 10, 2020, the recently generated swR embryo was transferred to a female swR recipient at Schwerin Zoo during her first cycle since the previous OPU in May. Estrous was indicated by mating with the infertile bull housed in the same facility.

- On June 16, 2020, a small press conference was held at the Serengeti-Park Hodenhagen. This helped to draw positive public attention to the park by reporting on the exceptionally successful OPU, and on the CoviD-19-related impairment to import a bull for natural mating.

- An early pregnancy examination on July 9, 2020 in the swR recipient in Schwerin Zoo found no signs of embryo implantation.

\subsubsection{Czech Republic}

Zoo Dvưr Králové is one of the largest zoos in the Czech Republic. Besides a large collection of diverse species, especially African ungulates and most 
notably rhinos, its most significant mission is to protect endangered and threatened wildlife species and offer environmental education programs. The zoo is specialized in African fauna and one of the most important breeders of African ungulates worldwide. Zoo Dvůr Králové is the only zoological institution to successfully breed NWR (Svitalsky et al., 1990). The last two remaining NWR females were born in Dvưr and sent to Ol Pejeta Conservancy in 2009. Zoo Dvůr Králové, the owner of Najin and Fatu, thus plays an important coordinating role in the BioRescue project.

Due to the pandemic, Zoo Dvůr Králové, similar to all Czech zoos, was temporarily closed to the public (March 16 to April 26, 2020). It was re-opened under the condition that the tickets would be sold only on-line to avoid queues at cash-desks, which reduced the number of visitors. This has caused major financial losses. Similar to the situation in Ol Pejeta Conservancy, fundraising revenue had to be directed to cover the running costs of the zoo rather than funding conservation projects and research. Apart from the financial losses, even after it re-opened to the public, the zoo had to cancel all of its environmental education programs due to the closure of schools and limits imposed on the number of people allowed to gather. During this period, Czech media demonstrated awareness by broadcasting how CoviD-19 had slowed down the efforts to save the NWR. They reported that since the OPU in the last two NWR planned for May 2020 had to be cancelled, approximately 10 less oocytes were harvested, which, on average, would have resulted in one further embryo for saving the subspecies.

\subsubsection{Italy}

Avantea Srl. is a leading laboratory in the field of advanced technologies in animal reproduction and biotechnology research, which has built its reputation over the past decades thanks to cutting-edge research and important scientific achievements of its founders. Despite the long and strict lockdown related to COVID-19 in Northern Italy, and despite Cremona being located virtually at the first epicenter of the European outbreak in spring 2020, shipment of samples was still possible and the generation of embryos not directly impaired. However, the reliability of the courier services was questionable and shipping times increased due to travel restrictions and limited flight schedules.

The ethical monitoring and research accompanying the rescue of the NWR was only slightly impaired.

Due to the lockdown, laboratories and offices at the University of Padova were closed and online-teaching and research was implemented. The team in charge of the ethical monitoring continued working from home, but it was not possible to follow the BioRescue team during their veterinary procedures. However, the ethical tool for assessment already developed within the project 
enabled to monitor at a distance the ethical risks that could occur during the procedures. The training process of the $\mathrm{PhD}$ students involved in the ethical assessment had to be suspended, but at the end of July the students were finally able to visit the Avantea laboratories to attend the OPU and IVF procedures. Therefore, despite all difficulties, the ethical assessment has always been performed and BioRescue procedures have uninterruptedly maintained high standards of quality and respect for the safety and welfare of both, researchers and animals involved. This assessment is crucial from the standpoint of the ethical acceptability of a conservation program where advanced and novel procedures are applied in conservation efforts to recover critically endangered taxa like the NWR.

\subsubsection{Japan}

Relatively few cases have been confirmed in Japan. As a consequence, the situation in the entire country has remained almost normal and the laboratory work has been largely unaffected. This ensured the continuation of the stem cell-related conservation research performed at Kyushu University, one of the most prestigious research-oriented universities in Japan.

\section{International Level}

On an international level, covid-19 related measures not only impaired a broad range of activities that require international cooperation, but also negatively impacted the financial situation of zoological institutions crucial to the success of the project.

The most striking obstacle has been imposed by international travel restrictions. The consortium partners of all involved countries had previously agreed upon collecting oocytes of the last two NWR every $3^{-4}$ months. This is considered a safe interval for the health of the females while maximizing the number of harvested oocytes, equivalent to potential future embryos and offspring. After two successful oocyte collections in August and December 2019, the next intervention, planned for the beginning of May 2020, had to be cancelled. In the meantime, possibilities for obtaining an exemption permit to enter Kenya by requesting support from the Kenyan Cabinet Secretary of the Ministry of Tourism and Wildlife, Kenya Wildlife Service (KWs), and the Czech and German embassies, were evaluated, and went as far as considering charter flight or Czech airforce transportation. Apart of their feasibility, these considerations were discarded due to the two-week quarantine that was mandatory both when entering Nairobi and after return to Europe. 
After the Kenyan borders reopened on August 1st, 2020, an oocyte collection in Kenya was performed as soon as mid-August. Many obstacles had to be overcome. With support of Czech authorities, both Germany (July 31, 2020) and the Czech Republic (August 5, 2020) were included in the list of countries considered safe for entry to Kenya. A health certificate with a negative test result for Covid-19 not older than 48 hours was requested upon entry to Kenya (later extended to 72 hours). Testing without symptoms or suspected infection was not readily available in Germany. Most laboratories require at least 24 hours for returning a test result. In combination with 12 hours flight time, this posed a challenging task. Reduced flight schedules complicated planning. Nevertheless, the German-Czech team boarded one of the first flights to Nairobi after re-opening of Kenyan borders. The idea to have a meeting of the consortium in Kenya at this occasion was rejected to keep the team as small as possible. The procedure was approved under the condition to fulfill the laws on hygiene and social distancing in Kenya. Therefore, masks had to be worn in public areas during the procedure, despite impaired communication and of vision if wearing glasses (Fig. 1). Sanitizers, a hand washing point, and a person to oversee

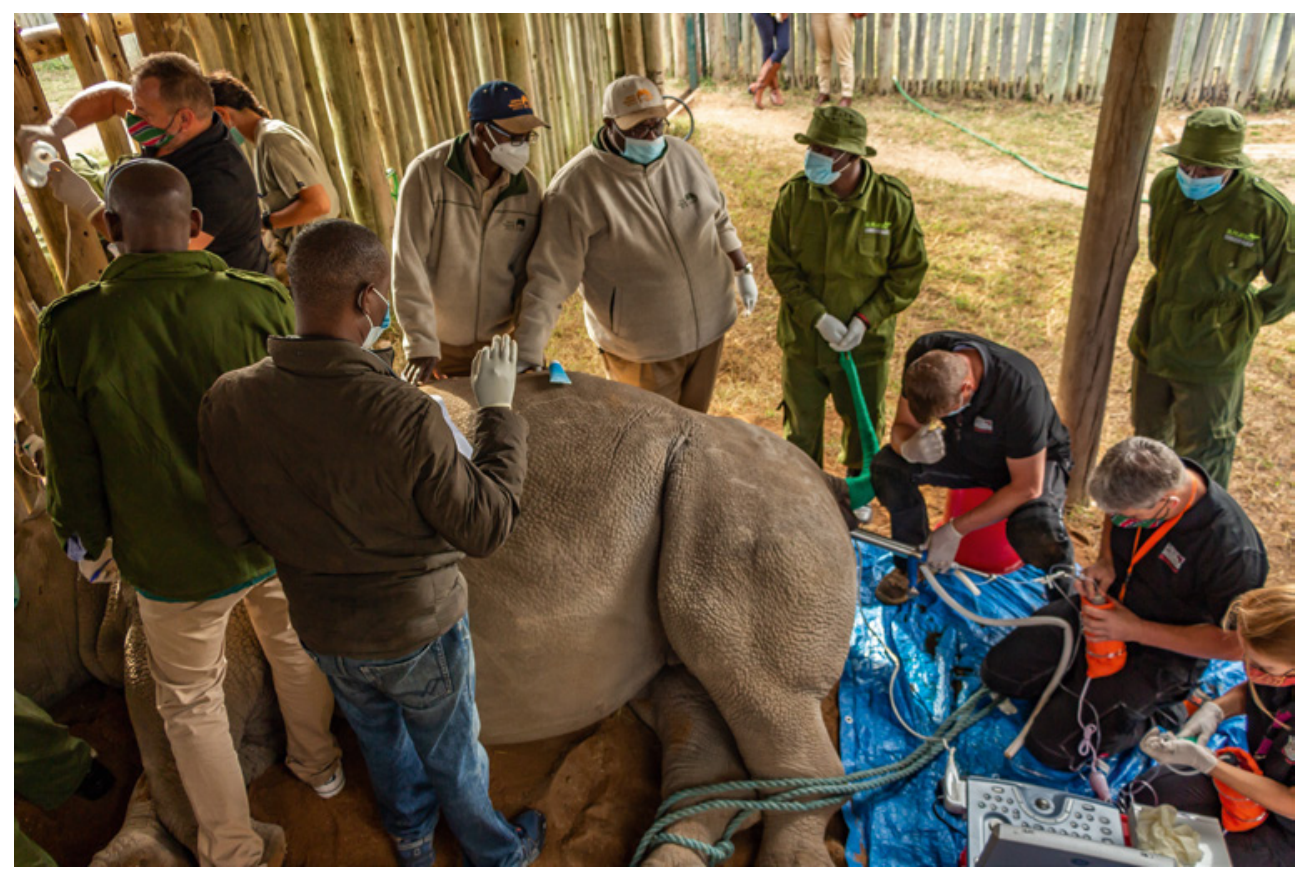

FIGURE 1 The international team performing an oocyte collection on Najin, one of the last northern white rhinoceroses wearing face masks on August 18, 2020 in Ol Pejeta, Kenya PHOTO TAKEN BY MARVIN MWARANGU 
adherence to social distancing and access of visitors to the procedure were installed. Ten oocytes were harvested and sent to Avantea laboratory in Italy, but none of them developed into an embryo. One plausible explanation for this is that the females - in absence of cycling activity - had retained follicles since the previous hormonal stimulation in December 2019. Due to the prolonged OPU-interval, and resulting increase in oocyte age, their quality was compromised.

Besides work on the last NWR, procedures planned on SWR in Europe were cancelled due to sudden changes in legislation and the risk of two-week quarantine. Additionally, unreliable courier services hindered work within Europe.

After suspension of the consortium meeting in Japan and a meeting in Kenya in the context of an OPU, place and time of an in person meeting will be determined according to the development of the travel restrictions related to COVID-19.

The planned visit of a postdoctoral researcher from MDC to Kyushu University, for which external third-party money has been obtained, had to be suspended due to travel restrictions. The scope of the exchange was knowledge transfer and training in special aspects of stem cell research. Its suspension delays research that was meant to capitalize on the newly acquired skills.

Finally, fundraising has become more difficult. Reduced numbers of visitors and international tourists in Ol Pejeta Conservancy, Zoo Dvůr Králové, and in national parks managed by Kenya Wildlife Service, have diminished the funds available for conservation work.

Despite the manifold hindrances imposed by the pandemic, several positive aspects warrant mentioning. One of them is certainly a general positive effect of reversed globalization on ecosystems and a reduction in ambient pollution. Besides such general considerations, two more project-specific positive opportunities have arisen.

Firstly, although the closure of European borders has kept us from performing OPUs and ETs in different European zoos, new opportunities have arisen in Germany, such as access to a young female swr due to the absence of breeding options other than aART. swR oocyte donor selection is restricted by the EEP to either long-term non-breeders, as identified by a thorough reproductive health check, or to suspended breeders, e.g., due to genetic overrepresentation in the EEP or tuberculosis complex-related reasons. Most female oocyte donors and candidates for embryo transfer in the program therefore are subfertile for 


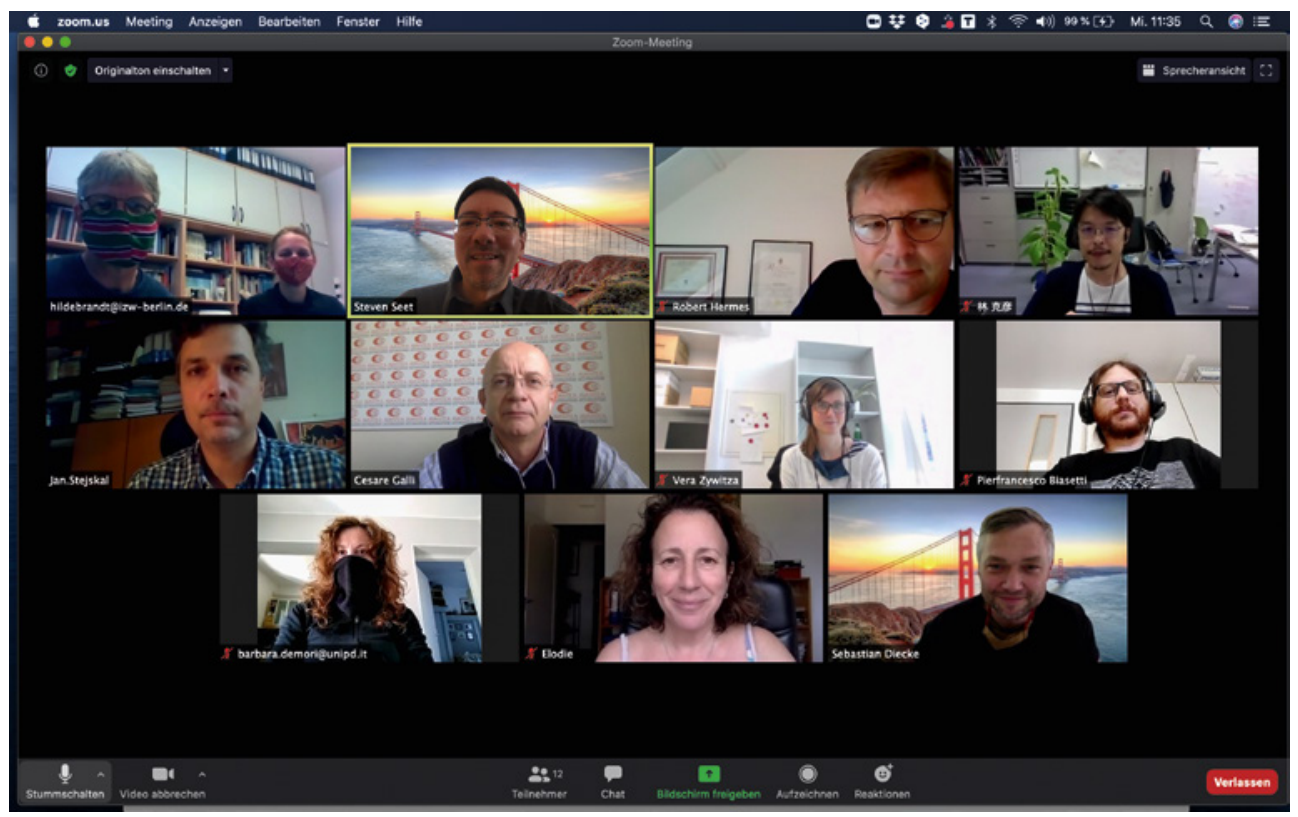

FIGURE 2 Online meeting of the BioRescue consortium on 30 of September, 2020

various reasons. The suspended transportation of a breeding bull has granted the project access to a healthy young swR with high potential for successful embryo transfer.

The second one is the newly established culture of online meetings of the consortium partners on a more regular basis (Fig. 2). This has resulted in a higher frequency of verbal exchange and an increased flexibility to spontaneously invite external guests. Before the pandemic, direct exchange of the entire team had been restricted to in person meetings, which took place approximately once a year and required considerable financial and time expenditure. The unique importance of direct interaction will still require in person meetings in the future. Nevertheless, the habit of additional and more frequent conference calls proved useful and will be maintained.

Among the several aforementioned negative effects of COVID-19, the most dramatic is the cancellation of planned procedures in Kenya and Europe due to travel restrictions. As a consequence, Najin and Fatu are growing older while precious time for generating more embryos and establishing successful 
embryo transfers in SWR is being irreversibly lost. The cancellation of the OPU and sterilization of a SWR teaser bull planned for May 2020 equals the approximated loss of ten NWR oocytes and one NWR embryo. The delay of possible NWR embryo transfers in Kenya will also decrease chances for NWR calves to grow up with individuals of their kind. This has practical and ethical implications for the outcome of the project, in other words for the chance of saving the species.

The difficulties in ordering and installing of laboratory equipment as well as the lack of direct exchange of ideas and skills are likely to result in further delay to the timelines that has been agreed upon in the framework of current funding schemes. This includes adherence to the work plan specified within the вм вF grant proposal. Funding schemes by the вмвF display little flexibility; the timely generation of published results is crucial for obtaining follow-up financing. Similarly, zoo Dvůr Králové faces difficulties to fulfill the timeline of the NWR grant provided by the Czech foundation Nadace ČEz. Also, a sudden redirection of national research funding away from conservation projects towards COVID-19 research or other areas of need, is a realistic scenario (Bates et al., 2020).

Additionally, scientific journalism and news have been dominated by COVID-19, leaving little space for reporting on scientific progress in other fields. This again negatively influences the outcome of fundraising campaigns. Resources generated by such campaigns in Germany, Czech Republic and Kenya are needed, as the вм вғ covers only operational costs, not infrastructure, such as for building an enclosure at $\mathrm{Ol}$ Pejeta Conservancy for sterilization of the teaser bull and for later separating sWR females for embryo transfer and pregnancy monitoring. The lack of financial resources due to reduced tourism and number of visitors to the zoological parks may further impair adherence to previously planned timelines. Disruption of this scheme by suspension of planned scientific work may compromise the long-term future of the project.

\section{7 Conclusions}

COVID-19, besides some unforeseen beneficial aspects, has generally attenuated both research and practical efforts to save the northern white rhinoceros. Major negative impacts have resulted from (1) restriction of working in laboratories, mainly affecting research in Germany; (2) travel restrictions within and between all involved countries, impairing also the exchange of knowledge, skills, samples, and materials, and the purchase and installation of relevant laboratory equipment; (3) financial losses due to the lack of visitors in the 
zoological facilities and conservancies, mainly in Kenya, the Czech Republic, and Germany; (4) deviation of media attention from topics such as conservation due to a strong focus on COVID-19 related stories. Last but not least, a very important ethical impact was that CoviD-19 has caused the idle passing of precious time for reaching mile-stones in the project, and most importantly for saving the last of their kind. The three main value dimensions involved in saving the NWR, i.e., conservation of the taxon, respect for the life of the individual animals involved, and respect for their welfare, highly depend on the ability to act in accordance with a reliable schedule.

Future losses may include the lack of funding for science by (a) delayed generation of scientific results which would be crucial to successfully apply for follow-up funding and (b) lack of money by stakeholders and governmental agencies due to the economic consequences of the pandemic.

The positive aspects emerging from the altered situation have been by far less pronounced, but were able to partly compensate for some obstacles imposed by the pandemic, i.e., a new culture of online conference calls facilitating communication, and access to a young female rhinoceros due to lack of a suitable breeding partner caused by European travel restrictions.

The probability of emerging zoonotic diseases has become an increasing threat to our own kind and will likely intensify in the future. It is clearly linked to the expansion of the human population, globalization of trade - mainly facilitated by ecological disruption, anthropogenic intrusion into novel habitats, and increasing movement of animal species (Brown, 2004; Chomel et al., 2007; Schmeller et al., 2020). Protecting and preserving viable and intact ecosystems including the keystone species which are crucial to sustain them therefore is of imminent importance for the future of humankind.

\section{Acknowledgements}

This study was funded by the BMBF project "BioRescue" (o1LC19o2A) and by the Nadace ČEZ project P R2O/1251; laboratory work at Avantea was generously supported by Richard McLellan. We further thank Ami Vitale for her support in communication and fundraising. Last but not least we thank the European Endangered Species Programme (EEP) for white rhinoceros, the European Association Zoos \& Aquaria (EAZA) Rhinoceros Taxon Advisory Group, as well as the supporting and participating zoological institutions Budapest Zoo, Zoo Cerza, Chorzow Zoo, Kolmarden Zoo, Longleat Safari Park, Montpellier Zoo, Pairi Daiza, Zoo Poznan, Salzburg Zoo, Schwerin Zoo, Serengeti-Park Hodenhagen, Zoo Thoiry, West Midlands Safari, and Zoo Zlin for their 
invaluable support. We would like to thank Merck KGaA for their support of our conservation research work.

\section{Supplementary Material}

BioRescue in times of CoviD-19; https://www.youtube.com/watch?time_conti nue $=10 \& v=J S T 4 L J 1 Q e 1 k \&$ feature $=$ emb_logo.

\section{References}

Bates, A.E., Primack, R.B., Moraga, P., \& Duarte, C.M. (2020). COVID-19 pandemic and associated lockdown as a "global human confinement experiment" to investigate biodiversity conservation. Biological Conservation, 108665.

Biggs, D., Courchamp, F., Martin, R., \& Possingham, H.P. (2013). Legal trade of Africa's rhino horns. Science, 339, 1038-1039.

Borzée, A., McNeely, J., Magellan, K., Miller, J.R.B., Porter, L, Dutta, T., Kadinjappalli, K.P., Sharma, S., Shahabuddin, G., Aprilinayati, F. \& Ryan, G.E. (2020). COVID-19 highlights the need for more effective wildlife trade legislation. Trends in Ecology \& Evolution, 35:12, 1052-1055.

Brown, C. (2004). Emerging zoonoses and pathogens of public health significance an overview. Revue scientifique et technique-office international des epizooties, 23:2, 435-442.

Buckley, R. (2020). Conservation implications of COVID-19: effects via tourism and extractive industries. Biological Conservation, 247, 108640.

Ceballos, G., Ehrlich, P.R., Barnosky, A.D., García, A., Pringle, R.M., \& Palmer, T.M. (2015). Accelerated modern human - induced species losses: Entering the sixth mass extinction. Science Advances, 1:5, e1400253.

Ceballos, G., Ehrlich, P.R., \& Dirzo, R. (2017). Biological annihilation via the ongoing sixth mass extinction signaled by vertebrate population losses and declines. Proceedings of the National Academy of Sciences, 114:30, E6o89-E6o96.

Chomel, B.B., Belotto, A., \& Meslin, F.X. (2007). Wildlife, exotic pets, and emerging zoonoses. Emerging Infectious Diseases, 13:1, 6.

Cromsigt, J.P., \& te Beest, M. (2014). Restoration of a megaherbivore: Landscape-level impacts of white rhinoceros in Kruger National Park, South Africa. Journal of Ecology, 102:3, 566-575.

Di Minin, E., Laitila, J., Montesino-Pouzols, F., Leader-Williams, N., Slotow, R., Goodman, P.S., Conway, A.J., \& Moilanen, A. (2015). Identification of policies for a sustainable 
legal trade in rhinoceros horn based on population projection and socioeconomic models. Conservation Biology, 29:2, 545-555.

Emslie, R. (2020). Northern white rhino. IUCN Red List of Threatened Species. Retrieved 8 May 2020.

Emslie, R.H. \& Brooks, M. (2002). How many southern white rhinos were there? A response to Kees Rookmaaker. Pachyderm, 33, 100-1.

Emslie, R.H., Milliken, T., \& Talukdar, B. (2013). African and Asian rhinoceroses status, conservation and trade. A report from the IUCN Species Survival Commission (IUCN/SSC) African and Asian rhino specialist groups and TRAFFIC to the CITES secretariat pursuant to resolution Conf. 9.14 (Rev. CoP15). Available from: http:// rhinos.org/wp-content/uploads/2015/o7/final-cop16-rhino-rpt.pdf.

Ferguson, N.M., Laydon, D., Nedjati-Gilani, G., Imai, N., Ainslie, K., Baguelin, M., Bhatia, S., Boonyasiri, A., Cucunubá, Z., Cuomo-Dannenburg, G., \& Dighe, A. (2020). Impact of non-pharmaceutical interven-tions (NPIs) to reduce COVID-19 mortality and healthcare demand. Imperial College COVID-19 Response Team, London, March, 16. https://www.imperial.ac.uk/media/imperial-college/medicine/sph/ide/gida -fellowships/Imperial-College-COVID19-NPI-modelling-16-o3-202o.pdf.

Haas T.C. \& Ferreira S.M. (2016). Conservation risks: when will rhinos be extinct? IEEE Transactions on Cybernetics. 46:8, 1721-1724.

Hermes, R., Hildebrandt, T.B., \& Göritz, F. (2018). Cryopreservation in rhinoceros setting a new benchmark for sperm cryosurvival. PLoS One, 13:7, eo200154.

Hikabe, O., Hamazaki, N., Nagamatsu, G., Obata, Y., Hirao, Y., Hamada, N., Shimamoto, S., Imamura, T., Nakashima, K., Saitou, M., \& Hayashi, K. (2016). Reconstitution in vitro of the entire cycle of the mouse female germ line. Nature, 539:7628, 299-303.

Hildebrandt, T.B., Hermes, R., Colleoni, S., Diecke, S., Holtze, S., Renfree, M.B., Stejskal, J., Hayashi, K., Drukker, M., Loi, P., Göritz, F., Lazzari, G., \& Galli, C. (2018). Embryos and embryonic stem cells from the white rhinoceros. Nature communications, 9:1, $1-9$.

Lacy, R.C. (1993). VORTEX: a computer simulation model for population viability analysis. Wildlife research, 20:1, 45-65.

Le Quéré, C., Jackson, R.B., Jones, M.W., Smith, A.J., Abernethy, S., Andrew, R.M., De-Gol, A.J., Willis, D.R., Shan, Y., Canadell, J.G., Friedlingstein, P., Creutzig, F. \& Peters, G.P. (2020). Temporary reduction in daily global $\mathrm{CO}_{2}$ emissions during the COVID-19 forced confinement. Nature Climate Change, 10, 647-653.

Lindsey, P., Allan, J., Brehony, P., Dickman, A., Robson, A., Begg, C., Bhammar, H., Blanken, L., Breuer, T., Fitzgerald, K., Flyman, M., Gandiwa, P., Giva, N., Kaelo, D., Nampindo, S., Nyambe, N., Steiner, K., Parker, A., Roe, D., Thomson, P., Trimble, M., Caron, A., \& Tyrrell, P. (202O). Conserving Africa's wildlife and wildlands through the COVID-19 crisis and beyond. Nature Ecology \& Evolution, 4, 1300-1310. 
Manenti, R., Mori, E., Di Canio, V., Mercurio, S., Picone, M., Caff, M., Brambilla, M., Ficetola, G.F., \& Rubolini, D. (2020). The good, the bad and the ugly of COVID-19 lockdown effects on wildlife conservation: Insights from the first European locked down country. Biological Conservation, 249, 108728.

Mbogo, R.W., \& Nyabadza, F. (2020). A COVID-19 model with a nonlinear incidence rate and intervention exit strategies for Kenya. Preprint from Research Square, 1-18. Muhammad, S., Long, X., \& Salman, M. (2020). COVID-19 pandemic and environmental pollution: a blessing in disguise? Science of the Total Environment, 728, 138820.

Owen-Smith, R.N. (1988). Megaherbivores: the influence of very large body size on ecology. Cambridge: Cambridge University Press.

Player, I. (1967). Translocation of white rhinoceros in South Africa. Oryx, 9:2, 137-150.

Rhino population figures. SaveTheRhino.org. www.savetherhino.org/rhino-info/population-figures/, 2021 [accessed 5 January 2021].

Rookmaaker, K. (200o). The alleged population reduction of the southern white rhinoceros (Ceratotherium simum simum) and the successful recovery. Säugetierkundliche Mitteilungen, 45:2, 55-70.

Rutz, C., Loretto, M.C., Bates, A.E., Davidson, S.C., Duarte, C.M., Jetz, W., Johnson, M., Kato, A., Kays, R., Mueller, T., Primack, R.B., Ropert-Coudert, Y., Tucker, M.A., Wikelski, M., Cagnacci, F. (2020). COVID-19 lockdown allows researchers to quantify the effects of human activity on wildlife. Nature Ecology and Evolution, 4:9, $1156-1159$.

Ryder, O.A., Friese, C., Greely, H.T., Sandler, R., Saragusty, J., Durrant, B.S., \& Redford, K.H. (2020). Exploring the limits of saving a subspecies: The ethics and social dynamics of restoring northern white rhinos (Ceratotherium simum cottoni). Conservation Science and Practice, 2:8, e241.

Saragusty, J., Diecke, S., Drukker, M., Durrant, B., Friedrich Ben-Nun, I., Galli, C., Göritz, F., Hayashi, K., Hermes, R., Holtze, S., Johnson, S., Lazzari, G., Loi, P., Loring, J., Okita, K., Renfree, M., Seet, S., Voracek, T., Stejskal, J., Ryder, O.A., \& Hildebrandt, T.B. (2016). Rewinding the process of mammalian extinction. Zoo Biology, 35, 280-292.

Schmeller, D.S., Courchamp, F., \& Killeen, G. (2020). Biodiversity loss, emerging pathogens and human health risks. Biodiversity and Conservation, 29, 3095-3102.

Svitalsky, M., Vahala, J., \& Spala, P. (1990). Breeding experience with northern white rhinos at zoo Dvur Kralove. Zoo Dvur Kralove, 199o, 282-286.

TRAFFIC. (2016). TRAFFIC's engagement on African rhinoceros conservation and the global trade in rhinoceros horn. TRAFFIC, Cambridge Conservation Biology, 31: 6, 2017. United Kingdom. Retrieved December 2016 from http://www.traffic.org/ rhinos/. 
Venter, Z.S., Aunan, K., Chowdhury, S., \& Lelieveld, J. (2020). COVID-19 lockdowns cause global air pollution declines. Proceedings of the National Academy of Sciences, 117:32, 18984-1899o.

Waldram, M.S., Bond, W.J., \& Stock, W.D. (2008). Ecological engineering by a megagrazer: white rhino impacts on a South African savanna. Ecosystems, 11:1, 101-112.

World Health Organization. (2020). Coronavirus disease 2019 (COVID-19) situation report-51. Geneva, Switzerland: World Health Organization. https://www.who.int/ docs/default-source/coronaviruse/situation-reports/20200311-sitrep-51-covid-19 .pdf?sfvrsn=1ba62e57_10. 